\title{
Decreasing prevalence but increasing importance of left ventricular dysfunction and reoperative surgery in prediction of mortality in coronary artery bypass surgery: Trends over 18 years
}

\author{
Khaled D. Algarni, MD, MHSc, Abdelsalam M. Elhenawy, MD, PhD, Manjula Maganti, MSc, \\ Susan Collins, BSc, and Terrence M. Yau, MD, MSc, FRCSC
}

\begin{abstract}
Objectives: The number of patients referred for coronary artery bypass grafting (CABG) has fallen, whereas their risk profile appears to be increasing. We evaluated changes in the predictors of hospital mortality among patients undergoing $\mathrm{CABG}$ during a span of 18 years.
\end{abstract}

\begin{abstract}
Methods: Data were collected prospectively for all patients undergoing isolated CABG $(n=23,445)$ from 1991 to 2008. To examine the effect of time on patients' risk profiles and outcomes, we divided patients into 3 time cohorts $(1991-1996, \mathrm{n}=8280 ; 1997-2002, \mathrm{n}=9801 ; 2003-2008, \mathrm{n}=5364)$. We used multivariable logistic regression model to identify predictors of mortality in the entire cohort and in each time cohort.
\end{abstract}

\begin{abstract}
Results: Hospital mortality declined from $2.4 \%$ (1991-1996) to $1.2 \%$ (2003-2008; $P<.0001)$. Urgent or emergency surgery, left ventricular dysfunction, reoperative CABG, increased age, female gender, hypertension, cardiogenic shock, congestive heart failure, peripheral vascular disease, left main disease, and earlier year of operation (1991-1996) were independent predictors of hospital mortality. The prevalence of most risk factors for mortality increased over the 18-year period of this study. In contrast, the prevalence of severe left ventricular dysfunction and reoperative CABG decreased significantly; however, their associated odds of mortality increased with time.
\end{abstract}

Conclusions: Whereas the prevalence of most risk factors increased with time, left ventricular dysfunction and reoperative CABG became significantly less common. However, the odds of mortality associated with these 2 predictors increased, indicating that although they occur less commonly, these 2 risk factors paradoxically play an increasingly important role in determining patient outcomes. (J Thorac Cardiovasc Surg 2012;144:340-6)

\section{$\mathcal{B}$ Supplemental material is available online.}

During the past 2 decades, increasingly older patients with more comorbidities have been referred to cardiac surgeons for coronary artery bypass grafting (CABG). Despite increasing patient risk factors over time, many studies have shown consistent improvement in operative outcomes. ${ }^{1-4}$

Over the past decade, however, many cardiac centers have noted decreasing volumes of isolated CABG. Aldea and colleagues ${ }^{5}$ reported a decrease of $37 \%$ in CABG volume, while

\footnotetext{
From the Division of Cardiovascular Surgery, Peter Munk Cardiac Center, University Health Network, Department of Surgery, University of Toronto, Toronto, Ontario, Canada.

Disclosures: Authors have nothing to disclose with regard to commercial support. Dr Yau is the Angelo \& Lorenza DeGasperis Chair in Cardiovascular Surgery Research.

Received for publication Feb 9, 2011; revisions received April 24, 2011; accepted for publication June 7, 2011; available ahead of print Nov 21, 2011

Address for reprints: Terrence M. Yau, MD, MSc, FRCSC, Division of Cardiovascular Surgery, Toronto General Hospital, 4N-470, 200 Elizabeth St, Toronto, Ontario, Canada M5G 2C4 (E-mail: terry.yau@uhn.on.ca; khaled.algarni@utoronto.ca). $0022-5223 / \$ 36.00$

Copyright (c) 2012 by The American Association for Thoracic Surgery doi:10.1016/j.jtcvs.2011.06.043
}

the volume of percutaneous coronary interventions (PCIs) increased by $71 \%$. This reduction in CABG volumes may have multiple effects, including an impact on hospital outcomes. A number of studies have reported associations between hospital volumes and outcomes, ${ }^{6-8}$ although this relationship remains controversial. In the context of decreasing volumes and increasing risk profiles for patients undergoing isolated $\mathrm{CABG}$, we analyzed our experience during an 18-year period to evaluate changes in patient risk profiles, document their outcomes, and determine changes in the independent predictors of hospital mortality.

\section{METHODS}

\section{Data Collection and Definitions}

Clinical, operative, and outcome data were collected prospectively in a computerized database for 23,445 consecutive patients undergoing isolated CABG at our institution between January 1, 1991, and December 31, 2008. Patients undergoing CABG with other concomitant procedures were excluded.

The study was approved by our institutional research ethics board. The primary outcome was hospital mortality, which was defined as any postoperative death during the index hospitalization. Variables collected included age, sex, left ventricular (LV) grade (by LV ejection fraction [LVEF]: grade $1, \mathrm{LVEF} \geq 60 \%$; grade $2, \mathrm{LVEF} 40 \%-59 \%$; grade 3 , LVEF $20 \%-39 \%$; grade 4 , LVEF $<20 \%$ ), previous CABG, urgency of operation (semiurgent, indicating an operation during the same admission as a cardiac 

Abbreviations and Acronyms
$\mathrm{BMI}=$ body mass index
$\mathrm{CABG}=$ coronary artery bypass grafting
$\mathrm{LV} \quad=$ left ventricular
LVEF $=$ left ventricular ejection fraction
$\begin{aligned} \mathrm{OPCAB}= & \text { off-pump coronary artery bypass } \\ \text { grafting } & \end{aligned}$
$\mathrm{OR}=$ odds ratio
PCI = percutaneous coronary intervention

catheterization or a cardiac event; urgent, indicating an operation within 72 hours of an event; emergency, indicating an operation within 12 hours of an event), number of diseased coronary arteries, presence of greater than a $50 \%$ stenosis of the left main coronary artery, and severity of angina, among other data.

\section{Statistical Analyses}

All statistical analyses were performed with SAS version 9.2 (SAS Institute, Inc, Cary, NC). To examine the effect of time on patient risk profiles and outcomes, we divided patients into 3 groups according to the year of operation (1991-1996, 1997-2002, and 2003-2008). Contingency table analysis was then used to evaluate changes with time in prevalence of preoperative, intraoperative, and postoperative variables. Univariate analyses were performed with $\chi^{2}$ or Fisher's exact test for categorical variables and analysis of variance for continuous variables. Variables that had a univariate $P$ value less than .25 or those of known clinical importance were submitted to a multivariable logistic regression model using a stepwise backward elimination method to calculate risk-adjusted mortality and factor-adjusted odds ratios (ORs). Model discrimination was evaluated by the area under the receiver-operator characteristic curve, and calibration was assessed with the Hosmer-Lemeshow goodness-of-fit statistic. The model was evaluated for multicolinearity with the variance inflation factor where variance inflation factor less than 2.5 indicates multicolinearity.

\section{RESULTS}

\section{Baseline Characteristics and Survival}

A total of 23,445 patients underwent isolated CABG between 1991 and 2008. A trend in volume of isolated CABG over the 18-year span is depicted in Figure 1. The number of patients increased progressively from 1991, peaked in 1998

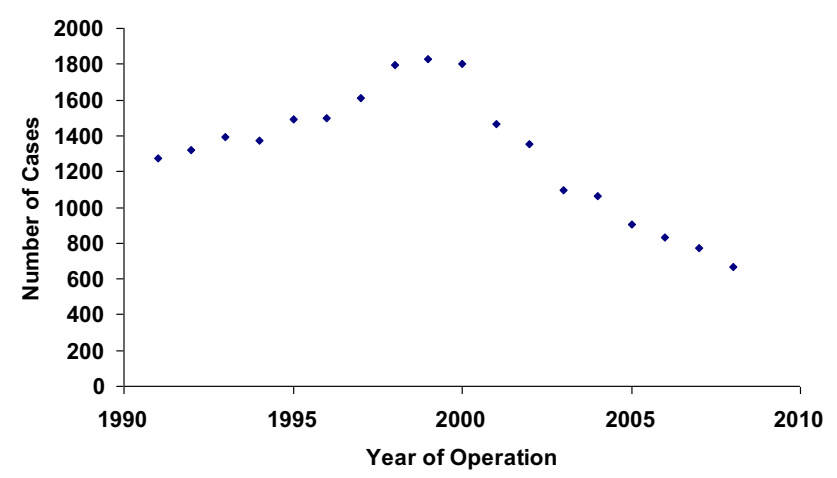

FIGURE 1. Trends in number of patients undergoing isolated coronary artery bypass grafting between 1991 and 2008 .
( $\mathrm{n}=1829)$, and then decreased substantially, by almost $70 \%$, from 1998 to 2008.

Preoperative patient characteristics are detailed in Table 1. The prevalence of most risk factors increased steadily. The rate of left main disease almost doubled between the first and the last time cohort (18.6\% vs 33.3\%). The number of patients undergoing semiurgent surgery has increased over the last 2 cohorts, whereas the number of patients undergoing elective, urgent, or emergency surgery has declined significantly. The prevalence of patients with LV dysfunction ( $\mathrm{LVEF}<60 \%$ ) has decreased over time, from $70 \%$ in the first time cohort to $50 \%$ in the last one. The prevalence of reoperative $\mathrm{CABG}$ declined as well. The changing risk profile of patients undergoing $\mathrm{CABG}$ during this 18-year span is depicted in Figure E1.

Intraoperative variables and postoperative outcomes are detailed in Table 2. The overall in-hospital mortality declined significantly from $2.4 \%$ in the first time cohort to $1.2 \%$ in the last one. Although the duration of intensive care unit stay has fluctuated, the duration of hospital stay declined significantly with time. Trends of postoperative outcomes are shown in Figure 2.

\section{Predictors of Hospital Mortality}

Analysis of the 23,445 patients undergoing operation during the entire 18 -year period of the study using stepwise multivariable logistic regression showed the following factors to be independent predictors of hospital mortality: increased age, female gender, hypertension, peripheral vascular disease, LV dysfunction, cardiogenic shock, congestive heart failure, reoperative $\mathrm{CABG}$, left main disease, urgency of surgery, and earlier year of operation (Table E1). Emergency CABG carried the most significant risk (OR, 4.5), followed by LVEF less than $20 \%(\mathrm{OR}, 4.2)$ and then reoperative $\mathrm{CABG}(\mathrm{OR}, 3)$.

\section{Trends in Multivariable Risk Factors for Hospital Mortality}

The changing trends in independent predictors of hospital mortality by time cohort are detailed in Table 3 . Unadjusted hospital mortality associated with individual predictors is shown in Figure E2.

LV dysfunction. Moderate (LVEF 20\%-39\%) and severe (LVEF $<20 \%$ ) LV systolic dysfunction were predictors of hospital mortality in the first time cohort. In the second cohort, however, LVEF did not predict mortality. LV systolic dysfunction then reappeared as a significant predictor of mortality in the last time cohort. The overall mortality for patients with an LVEF less than $20 \%$ declined significantly from $11.1 \%$ in the first time cohort to $6.4 \%$ and $6.3 \%$ in the second and the third time cohorts, respectively. Similarly, for patients with an LVEF of $20 \%$ to $39 \%$, the observed mortality declined from $3.6 \%$ in the first time cohort to $1.8 \%$ in the second and $2.3 \%$ in the last time cohort. 
TABLE 1. Preoperative patient's baseline characteristics by year group

\begin{tabular}{|c|c|c|c|c|}
\hline Variable & 1991-1996 & 1997-2002 & 2003-2008 & $P$ value \\
\hline No. of patients & 8280 & 9801 & 5364 & \\
\hline Age $(y)$ mean \pm SD & $62 \pm 9.8$ & $63.6 \pm 9.9$ & $65.3 \pm 10.1$ & $<.0001$ \\
\hline Less than $65(\%)$ & 56.4 & 49.9 & 45.3 & $<.0001$ \\
\hline $65-74(\%)$ & 34.5 & 36.5 & 35.1 & \\
\hline$\geq 75(\%)$ & 9.0 & 13.6 & 19.7 & \\
\hline $\mathrm{BMI}($ mean $\pm \mathrm{SD})$ & $27.5 \pm 4.8$ & $27.9 \pm 5.1$ & $28.3 \pm 5.2$ & $<.0001$ \\
\hline Female $(\%)$ & 20.7 & 21.5 & 21.2 & .40 \\
\hline Diabetes mellitus (\%) & 24.5 & 30.7 & 37.3 & $<.0001$ \\
\hline Hypertension (\%) & 50.8 & 58.7 & 72.9 & $<.0001$ \\
\hline Hyperlipidemia (\%) & 56.7 & 73.8 & 91.2 & $<.0001$ \\
\hline Positive family history (\%) & 66.5 & 61.03 & 59.3 & $<.0001$ \\
\hline \multicolumn{5}{|l|}{ Angina $(\%)$} \\
\hline Stable & 33.8 & 35.8 & 37.2 & $<.0001$ \\
\hline Crescendo & 33.4 & 32.0 & 29.7 & \\
\hline Acute coronary insufficiency & 30.8 & 29.9 & 24.9 & \\
\hline Preoperative MI (\%) & 16.8 & 21.5 & 23.3 & $<.0001$ \\
\hline Preoperative cardiogenic shock $(\%)$ & 1.3 & 1.2 & 1.2 & .7 \\
\hline Congestive heart failure $(\%)$ & 8.9 & 9.3 & 10.1 & .04 \\
\hline Preoperative IABP (\%) & 3.8 & 3.1 & 3 & .01 \\
\hline \multicolumn{5}{|l|}{$\operatorname{LVEF}(\%)$} \\
\hline$>60 \%$ & 29.7 & 36.8 & 49.1 & $<.0001$ \\
\hline $40 \%-60 \%$ & 45.1 & 41.6 & 33.2 & \\
\hline $20 \%-40 \%$ & 22.0 & 19.0 & 16.0 & \\
\hline$<20 \%$ & 3.2 & 2.6 & 1.8 & \\
\hline Left main disease $(\%)$ & 18.6 & 21.2 & 33.3 & $<.0001$ \\
\hline Triple-vessel disease $(\%)$ & 74.4 & 76.1 & 82.3 & $<.0001$ \\
\hline Preoperative stroke $(\%)$ & 8.2 & 8.5 & 8.7 & 6 \\
\hline Peripheral vascular disease $(\%)$ & 14.2 & 16.4 & 20.3 & $<.0001$ \\
\hline Reoperative CABG (\%) & 6.9 & 4.0 & 2.6 & $<.0001$ \\
\hline Previous PCI \pm stents & 10.4 & 8.7 & 10.5 & $<.0001$ \\
\hline \multicolumn{5}{|l|}{ Urgency of surgery $(\%)$} \\
\hline Elective & 54.6 & 49.4 & 50.6 & $<.0001$ \\
\hline Semiurgent & 29.6 & 41.4 & 40.1 & \\
\hline Urgent & 14.4 & 8.6 & 9.4 & \\
\hline Emergency & 1.4 & 0.5 & 0.5 & \\
\hline
\end{tabular}

$S D$, Standard deviation; $B M I$, body mass index; $M I$, myocardial infarction; $I A B P$, intra-aortic balloon pump; $L V E F$, left ventricular ejection fraction; $C A B G$, coronary artery bypass grafting; $P C I$, percutaneous coronary intervention.

Although the prevalence of LVEF less than $20 \%$ declined significantly with time, the associated ORs for mortality increased over the past decade, from 2.5 in the second time cohort to 3.8 in the last one.

Reoperative CABG. The prevalence of reoperative CABG decreased from $6.9 \%$ in the first cohort to $2.6 \%$ in the last one. In contrast, the risk of hospital mortality in this group, relative to patients undergoing primary CABG, has increased over time (ORs, 2.8, 3.1, and 3.5 in the first, second and third time cohorts, respectively). Inasmuch as the mortality of reoperative $\mathrm{CABG}$ did not change significantly during the entire span of this study, this increase in ORswas driven largely by improving outcomes in patients undergoing first-time operations.

Urgency of surgery. Observed mortality for patients undergoing urgent surgery declined in the most recent cohort.
Similarly, mortality for patients undergoing elective or semiurgent surgery declined significantly during the 18year span of this study. In contrast, patients requiring emergency CABG continued to be at increased risk. The OR for mortality associated with emergency surgery has fluctuated over the 3 time cohorts. It was lowest in the first cohort (OR, $3.5)$ and higher in the later cohorts (ORs, 12.7 and 7.1).

Age and gender. Patients aged 75 years and older had significantly higher hospital mortality than those younger than 75 years, but the mortality for elderly patients decreased substantially from $5.8 \%$ in the first time cohort to $2 \%$ in the last one. Hospital mortality also declined in younger ( $<70$ years) patients, falling from $1.7 \%$ in the first cohort to $0.8 \%$ in the last one.

In the last cohort, hospital mortality among female patients fell to $1.5 \%$ compared with $4 \%$ in the first cohort. 
TABLE 2. Operative data and postoperative outcomes by year group

\begin{tabular}{|c|c|c|c|c|}
\hline Variable & 1991-1996 & 1997-2002 & 2003-2008 & $P$ value \\
\hline \multicolumn{5}{|l|}{ Intraoperative variables } \\
\hline LITA use $(\%)$ & 86.1 & 89.6 & 91.3 & $<.0001$ \\
\hline RITA use $(\%)$ & 2.2 & 5.7 & 7.9 & $<.0001$ \\
\hline Radial artery use* $(\%)$ & - & 4.1 & 2.1 & $<.0001$ \\
\hline No. of grafts & $3.6 \pm 0.9$ & $3.5 \pm 0.9$ & $3.4 \pm 0.9$ & $<.0001$ \\
\hline CPB time (min) & $86 \pm 29.2$ & $85 \pm 32.6$ & $81.1 \pm 33.4$ & $<.0001$ \\
\hline Crossclamping time (min) & $61.7 \pm 18.6$ & $63.2 \pm 24.2$ & $62.9 \pm 28.1$ & $<.0001$ \\
\hline \multicolumn{5}{|l|}{ Cardioplegia technique $(\%)$} \\
\hline Intermittent cold antegrade & 71.7 & 74.1 & 86.3 & $<.0001$ \\
\hline Warm or tepid cardioplegia & 16.9 & 10.6 & 1.6 & \\
\hline Retrograde & 6 & 1 & 0.2 & \\
\hline Off pump & 0.1 & 5.1 & 8.5 & \\
\hline \multicolumn{5}{|l|}{ Postoperative outcomes } \\
\hline Mortality (\%) & 2.4 & 1.4 & 1.2 & $<.0001$ \\
\hline Inotrope use $>30 \min (\%)$ & 33.8 & 33.1 & 38.1 & $<.0001$ \\
\hline Low-output syndrome (\%) & 8.0 & 4.8 & 2.9 & $<.0001$ \\
\hline Postoperative IABP (\%) & 4.9 & 3.2 & 2.2 & $<.0001$ \\
\hline Postoperative MI (\%) & 2.8 & 2.7 & 2.4 & .3 \\
\hline Postoperative stroke $(\%)$ & 1.4 & 1.2 & 1.1 & .4 \\
\hline Postoperative renal failure $(\%)$ & 0.8 & 1.0 & 1.2 & .2 \\
\hline Pulmonary complications $(\%)$ & 9.9 & 7.5 & 8.4 & $<.0001$ \\
\hline \multicolumn{5}{|l|}{ Sternal wound infection (\%) } \\
\hline Superficial & 1.9 & 1.6 & 1.2 & .006 \\
\hline Deep & 0.9 & 0.8 & 0.6 & \\
\hline Sepsis & 0.7 & 1 & 1.6 & $<.0001$ \\
\hline Resternotomy for bleeding ( $\%$ ) & 1.4 & 2.4 & 2.8 & $<.0001$ \\
\hline Transfused patients ( $\%)$ & 50.6 & 44.3 & 62.2 & $<.0001$ \\
\hline Units of packed RBC transfused & $1.4 \pm 2.7$ & $1.2 \pm 2.8$ & $1.9 \pm 2.7$ & $<.0001$ \\
\hline Duration of ventilation (h) & $22.6 \pm 63.5$ & $14.7 \pm 49.7$ & $17.2 \pm 60.6$ & $<.0001$ \\
\hline Duration of ICU stay (h) & $52.8 \pm 98.5$ & $45.4 \pm 76.4$ & $52.6 \pm 129$ & $<.0001$ \\
\hline Postoperative hospital stay (d) & $9.4 \pm 9.4$ & $7.9 \pm 9.5$ & $7.7 \pm 7.9$ & $<.0001$ \\
\hline
\end{tabular}

LITA, Left internal thoracic artery; RITA, right internal thoracic artery; $C P B$, cardiopulmonary bypass; $I A B P$, intra-aortic balloon pump; $M I$, myocardial infarction; $R B C$, red blood cells; ICU, intensive care unit. *Radial artery data was not collected during the first time cohort (1991-1996).

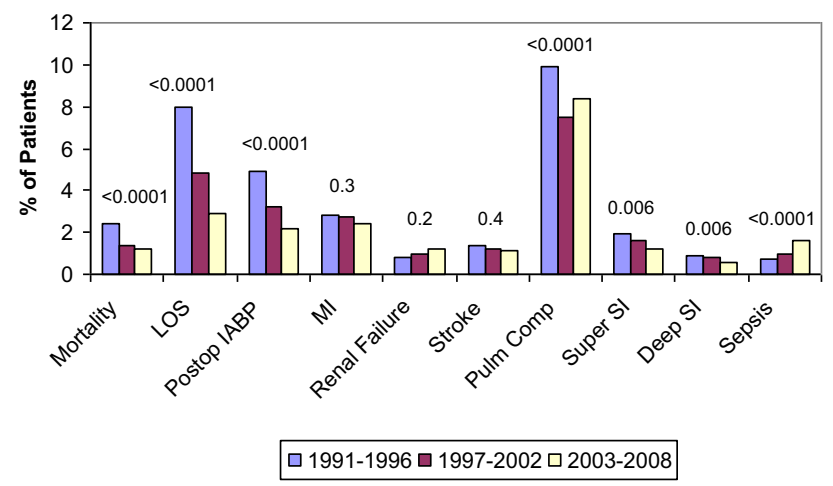

FIGURE 2. Trends in hospital outcomes: operative mortality, low-output syndrome ( $L O S)$, postoperative intra-aortic balloon pump (IABP) use, perioperative myocardial infarction $(M I)$, postoperative renal failure, stroke, pulmonary complications (Pulm Comp), superficial sternal incision infection (Super SI), deep sternal infections (Deep SI), and sepsis. $P$ values are included in the figure.
Furthermore, in the last cohort (2003-2008), there was no significant difference in observed mortality between men and women, $1.1 \%$ and $1.5 \%$, respectively $(P=.2)$. Female gender was a predictor of hospital mortality during the first and second time cohorts but not in the last one.

\section{DISCUSSION}

We found in this study that the prevalence of most risk factors that have consistently predicted in-hospital mortality in previous studies ${ }^{2-4,9-12}$ increased steadily with time. These factors included advanced age, female gender, hypertension, left main disease, preoperative myocardial infarction, congestive heart failure, and peripheral vascular disease. This was not a surprise for us; indeed, we and others have previously reported similar findings. ${ }^{2-4,10-12}$ What was surprising, however, was the decrease in prevalence of LV dysfunction and reoperative CABG and the associated increase in risk of death for these subgroups in our most recent cohort. This reduction in the prevalence of reoperative $\mathrm{CABG}$ and $\mathrm{LV}$ dysfunction, with an 
TABLE 3. Changing trends in multivariable risk factors by year group (odds ratios)

\begin{tabular}{|c|c|c|c|}
\hline Variable & 1991-1996* & $1997-2002 \dagger$ & 2003-2008 \\
\hline Emergency surgery & 3.5 & 12.7 & 7.1 \\
\hline Urgent surgery & - & 6.5 & 3.6 \\
\hline Reoperative CABG & 2.8 & 3.1 & 3.5 \\
\hline LVEF $<20 \%$ & 6.6 & - & 3.8 \\
\hline LVEF $20 \%-40 \%$ & 2.7 & - & 2.6 \\
\hline Congestive heart failure & 1.7 & 2.3 & 2.5 \\
\hline Age & 1.050 & 1.039 & 1.044 \\
\hline Female sex & 1.6 & 1.7 & - \\
\hline Hypertension & 1.5 & 1.8 & - \\
\hline \multicolumn{4}{|c|}{$\begin{array}{l}C A B G \text {, Coronary artery bypass grafting; } L V E F \text {, left ventricular ejection fraction. The } \\
\text { numbers in the last three columns represent odds ratios. *The area under the ROC } \\
\text { curve was } 0.78 \text {. The Hosmer-Lemeshow goodness-of-fit } P \text { value was } .5 \text {. } † \text { The area un- } \\
\text { der the receiver-operator characteristic curve was } 0.82 \text {. The Hosmer-Lemeshow } \\
\text { goodness-of-fit } P \text { value was } 0.75 \text {. } \ddagger \text { The area under the receiver-operator characteristic } \\
\text { curve was } 0.79 \text {. The Hosmer-Lemeshow goodness-of-fit } P \text { value was } .32 \text {. The } \\
\S \text { Emergency patients from catheterization laboratories or emergency units of same } \\
\text { or other hospitals. }\end{array}$} \\
\hline
\end{tabular}

associated and apparently paradoxical increase in their odds of death, has not to our knowledge been reported before.

The independent predictors of in-hospital mortality in our cohort are generally similar to those previously described by Davierwala, Maganti, and $\mathrm{Yau}^{2}$ with the exception of diabetes, which was not found to be a predictor of in-hospital mortality in our series. Emergency surgery carried the highest risk of mortality in our overall series (OR, $4.5 ; 95 \%$ confidence intervals $[\mathrm{CI}], 2.4-8.4$ ), followed by severe $\mathrm{LV}$ dysfunction (LVEF $<20 \%$ [OR, 4.2; 95\% CI, 2.7-6.5]) and then reoperative $\mathrm{CABG}(\mathrm{OR}, 3 ; 95 \% \mathrm{CI} 2.2-4.0)$. These findings are in agreement with those of Abramov and colleagues, ${ }^{4}$ who reported urgency of surgery as the strongest predictor of CABG mortality (OR, 4.5), followed by reoperative CABG and then LVEF less than 35\%. Similarly, Jones and associates ${ }^{10}$ reported urgency of surgery as the most significant predictor of mortality after CABG. Davierwala, Maganti, and $\mathrm{Yau}^{2}$ found LVEF less than 20\% as the most significant predictor of in-hospital mortality, followed by emergency surgery and then reoperative CABG.

\section{Dysfunction}

Contrary to our initial assumptions, the prevalence of patients with moderate to severe LV dysfunction (LVEF $<40 \%$ ) decreased steadily with time. We hypothesized that this decline might be related to a shift of patients with poor LV function from isolated CABG to combined CABG and valvular surgery, particularly mitral surgery. Exploratory analyses of our institutional data demonstrated a similar reduction in the prevalence of $L V$ dysfunction in patients undergoing combined aortic valve surgery and CABG (prevalence of LVEF $<40 \%$ of $22.8 \%, 20.7 \%$, and $13.8 \%$ for the first, second, and third time cohorts, respectively). In contrast, the prevalence of LVEF less than
$40 \%$ among patients who underwent combined mitral valve surgery and $\mathrm{CABG}$ has increased progressively with time $(30.6 \%, 32.8 \%$, and $38.7 \%$ for the first, second, and third time cohorts, respectively). This shift of patients with LVEF less than $40 \%$ from the isolated CABG group to the combined $\mathrm{CABG}$ and mitral valve surgery group over the past 2 decades appears to explain most of the reduced prevalence of moderate to severe LV systolic dysfunction in our patients with isolated CABG. However, our data cannot clarify whether there was a simultaneous decrease in the referral of patients with $\mathrm{LV}$ dysfunction for CABG in favor of PCI.

Hospital mortality in patients with significant LV dysfunction (LVEF $<40 \%$ ) fell by almost $50 \%$, from $4.5 \%$ in the first cohort to $2.3 \%$ in the second one, but was essentially unchanged $(2.7 \%)$ in the last cohort. Surprisingly, the ORs for mortality associated with LV dysfunction increased over the past decade, from 2.5 in the second cohort to 3.8 in the last one. Thus, although LV dysfunction is observed less commonly in patients with isolated CABG, its relative importance in determining survival has increased rather than decreased over the past decade.

Whereas moderate (LVEF 20\%-39\%) and severe LV dysfunction (LVEF $<20 \%$ ) were both independent predictors of in-hospital mortality for the entire cohort of 23,445 patients, neither level of LV dysfunction was predictive of mortality in the second cohort (1997-2002), despite the large sample size of 9801 patients. Other investigators have also reported that LV dysfunction was no longer predictive of mortality in the middle of this last decade. Filsoufi and colleagues ${ }^{13}$ reported that LVEF less than $30 \%$ was not an independent predictor of early mortality (OR, 1.43; $95 \%$ CI, 0.72-2.86; $P=.3$ ). Similarly, Davierwala and associates, ${ }^{2}$ who analyzed the impact of LVEF on patients undergoing CABG during 3 time periods from 1990 to 2001, showed that the impact of LVEF on early mortality declined over time so that low LVEF no longer predicted mortality in the last period of their study. Sabik and associates ${ }^{14}$ also found that later date of operation decreased mortality in patients with LV dysfunction $(P=.05)$, and by the end of their study, poor LV function was no longer associated with hospital death. In contrast, the most recent cohort of our current series suggests that as overall results improve, and despite the decreasing prevalence of LV dysfunction, its relative importance in determining outcomes is again increasing.

\section{Reoperative CABG}

Although the proportion of reoperative CABGs increased over the 1990s in many centers, ${ }^{14,15}$ we observed a steady decrease in reoperative $\mathrm{CABG}$ over the past 18 years. This decline may have been related to more aggressive use of PCI in patients with graft atherosclerosis, and perhaps to greater graft longevity, with the near-universal adoption of aggressive lipid-lowering agents as well as 
other secondary prevention measures. However, our data do not permit more than speculation as to these causes.

Similar to our findings in patients with LV dysfunction, the ORs for mortality associated with reoperative CABG increased over time, from 2.8 in the first cohort to 3.5 in the last cohort, even as the prevalence of redo surgery fell. Unadjusted mortality among patients undergoing reoperative CABG decreased from $5.8 \%$ in the first time cohort to $3.3 \%$ and $3.6 \%$ in the second and third cohorts, so it appears that overall improvements in outcomes are unmasking a more predictive role of reoperative surgery.

Many studies, including reports from multicenter registry data, suggest that redo $\mathrm{CABG}$ is still a significant undertaking, with many centers reporting mortality rates from $5 \%$ to $12 \%{ }^{14-18} \mathrm{~A}$ recent multicenter study by Yap and associates ${ }^{18}$ reported results similar to ours, with operative mortality of $4.8 \%$ for redo CABG compared with $1.8 \%$ for first-time CABG $(P<.001)$. After adjustment, redo surgery remained a predictor for operative mortality (OR, 2.1; 95\% CI, 1.3-3.6).

\section{Urgency of Surgery}

The proportion of patients referred for urgent CABG declined in our series from $14.4 \%$ in the first cohort to $9.4 \%$ in the last one, whereas the prevalence of truly emergency or salvage operation decreased from $1.4 \%$ to $0.5 \%$. Ferguson and colleagues ${ }^{12}$ have reported a similar reduction in the prevalence of emergency and salvage operations. This decline is likely attributable to the advances in PCI with increased operator experience and widespread adoption of coronary stents, ${ }^{19-21}$ use of glycoprotein IIb/IIIa agents, ${ }^{22,23}$ upfront loading with clopidogrel, ${ }^{24}$ and the more recent introduction of percutaneous ventricular assist devices for high-risk coronary interventions, ${ }^{25}$ all occurring over the time span of this series.

Although emergency CABG is less common now, as cardiologists using catheterization are increasingly able to stent their way out of trouble, patients now meeting the criteria for emergency surgery may represent an even higher-risk subset in which initial salvage attempts have been unsuccessful and in whom hemodynamic instability has been prolonged. In this series, the unadjusted mortality for emergency surgery increased from $7.6 \%$ in the first cohort to $10.3 \%$ in the last one, and the OR for mortality increased from 3.5 in the first cohort to 12.7 and 7.1 in the subsequent cohorts. Whereas the markedly elevated ORs, particularly in the second cohort, were associated with a relatively small number of events even in this large group, and therefore with wide CIs, it is clear that the importance of emergency $\mathrm{CABG}$ in determining survival is increasing rather than decreasing over time. This trend of decreasing prevalence of emergency CABG but increasing mortality was also reported by Haan and colleagues ${ }^{26}$ in a study of the Society of Thoracic Surgeons database, in which they found that the proportion of isolated CABGs performed on an emergency basis after PCI decreased over the period from 1994 to 1999 from $2.9 \%$ to $0.8 \%$, whereas operative mortality increased from $8.0 \%$ to $9.3 \%(P<.001)$.

\section{Other Trends Occurring During the Time Frame of This Study}

The 3 time periods evaluated in this 18 -year study corresponded generally to periods of increasing use of balloon angioplasty, bare metal stents, and drug-eluting stents, respectively. These trends in use of PCI have influenced the rate of, and risk profile of, patients referred for CABG in many institutions. We therefore chose to divide this period of study into 3 equal eras of 6 years.

The prevalence of off-pump CABG (OPCAB) in our institution increased slightly but steadily over the last 2 eras of this study, representing $5.1 \%$ and $8.5 \%$ of CABG cases in the second (1997-2002) and the latest (2003-2008) eras, respectively. The overall risk profile of patients who underwent $\mathrm{OPCAB}$ was comparable with that of patients who underwent on-pump CABG, but the prevalence of peripheral vascular disease was markedly higher in the OPCAB group ( $35.8 \%$ vs $16.4 \%$ and $42.4 \%$ vs $20.3 \%$ in the second and the latest eras, respectively). Mortality in OPCAB patients compared favorably with that in the on-pump group ( $0.8 \%$ vs $1.4 \%$ and $0.9 \%$ vs $1.2 \%$ in the second and the latest time cohorts, respectively). Despite the higher prevalence of peripheral vascular disease among patients undergoing $\mathrm{OPCAB}$, the prevalence of postoperative stroke was low, $0 \%(0 / 503)$ and $0.2 \%(1 / 455)$ in the second and the latest eras of this study, respectively.

There was a small but significant increase in the mean body mass index (BMI) of our patients over the span of this study $(27.5 \pm 4.8,27.9 \pm 5.1$, and $28.3 \pm 5.2$ in the first, second, and third eras, respectively; $P<.0001$ ). Most patients $(93 \%)$ had a BMI in the 18 to 35 range. About $6 \%$ of patients had a BMI greater than 35 and a few patients $(<1 \%)$ had a BMI less than 18. Extremely high BMI (>35) was associated with higher morbidity, manifested mainly as a higher prevalence of postoperative superficial $(4.1 \%)$ and deep $(2.2 \%)$ sternal infections. As well, these patients tended to have a slightly higher mortality $(2.1 \%)$, although this difference did not reach statistical significance. Patients with extremely low BMI $(<18)$ had a significantly higher risk of mortality $(5.2 \%, 4 / 77)$ and stroke $(3.9 \%, 3 / 77)$ compared with other patients $(P=.008)$.

Despite the prospective nature of the data collection, this study remains a retrospective review of a single center's experience and therefore has all of the caveats of such a study. Although the experience of other cardiac surgical units over the past 2 decades may have varied to some degree, we believe that the trends observed at our institution are likely representative of those occurring in other tertiary and quaternary institutions. Two decades of coronary surgery 
were included in this study, during which both surgical and medical therapy for coronary disease changed. A long observation period has advantages as well, including many years of data available for analysis and the ability to evaluate the potential effects of gradual changes in referral patterns and surgical approaches. Because our data do not include information on all patients evaluated by the cardiologists, however, we cannot separate the effects of changes in referral patterns from cardiologists from changes in acceptance for surgery by surgeons. Finally, although our database accurately captures LV systolic dysfunction, it unfortunately does not permit analysis of diastolic dysfunction, which may explain the limited correlation between poor LVEF and the prevalence of congestive heart failure.

In summary, our study showed a decreasing prevalence of the 3 risk factors previously identified as most predictive of hospital mortality, including LV systolic dysfunction, reoperative $\mathrm{CABG}$, and emergency surgery. Despite their declining prevalence, the ORs for mortality associated with all 3 predictors increased over the 18-year span of this series, as overall results continued to improve in the past decade, but the results in these 3 subgroups of patients remained constant. Despite previous advances in the care of patients with LV dysfunction and those who need reoperative or emergency CABG, these patients remain a challenge to cardiac surgeons and require novel strategies to improve outcomes further.

\section{References}

1. Baillot RG, Joanisse DR, Stevens LM, Doyle DP, Dionne B, Lellouche F. Recent evolution in demographic and clinical characteristics and in-hospital morbidity in patients undergoing coronary surgery. Can J Surg. 2009;52:394-400.

2. Davierwala PM, Maganti M, Yau TM. Decreasing significance of left ventricular dysfunction and reoperative surgery in predicting coronary artery bypass grafting-associated mortality: a twelve-year study. J Thorac Cardiovasc Surg. 2003;126:1335-44

3. Sadeghi N, Sadeghi S, Mood ZA, Karimi A. Determinants of operative mortality following primary coronary artery bypass surgery. Eur J Cardiothorac Surg. 2002;21:187-92.

4. Abramov D, Tamariz MG, Fremes SE, Guru V, Borger MA, Christakis GT, et al. Trends in coronary artery bypass surgery results: a recent, 9-year study. Ann Thorac Surg. 2000;70:84-90.

5. Aldea GS, Mokadam NA, Melford R Jr, Stewart D, Maynard C, Reisman M, et al. Changing volumes, risk profiles, and outcomes of coronary artery bypass grafting and percutaneous coronary interventions. Ann Thorac Surg. 2009;87: 1828-38.

6. Dudley RA, Johansen KL, Brand R, Rennie DJ, Milstein A. Selective referral to high-volume hospitals estimating potentially avoidable deaths. JAMA. 2000;283: 1159-66.

7. Halm EA, Lee C, Chassin MR. Is volume related to outcome in health care? A systematic review and methodologic critique of the literature. Ann Intern Med. 2002;137:511-20.

8. Carey JS, Danielsen B, Milliken J, Li Z, Stabile BE. Narrowing the gap: early and intermediate outcomes after percutaneous coronary intervention and coronary artery bypass graft procedures in California, 1997 to 2006. J Thorac Cardiovasc Surg. 2009;138:1100-7.
9. Noyez L, Janssen DP, van Druten JA, Skotnicki SH, Lacquet LK. Coronary bypass surgery: what is changing? Analysis of 3834 patients undergoing primary isolated myocardial revascularization. Eur J Cardiothorac Surg. 1998; 13:365-9.

10. Jones RH, Hannan EL, Hammermeister KE, Delong ER, O'Connor GT, Luepkar RV, et al. Identification of preoperative variables needed for risk adjustment of short-term mortality after coronary artery bypass graft surgery: the Working Group Panel on the Cooperative CABG Database Project. J Am Coll Cardiol. 1996;28:1478-87.

11. Ivanov J, Weisel RD, David TE, Naylor CD. Fifteen-year trends in risk severity and operative mortality in elderly patients undergoing coronary artery bypass graft surgery. Circulation. 1998;97:673-80.

12. Ferguson TB Jr, Hammill BG, Peterson ED, DeLong ER, Grover FL. A decade of change-risk profiles and outcomes for isolated coronary artery bypass grafting procedures, 1990-1999: a report from the STS National Database Committee and the Duke Clinical Research Institute. Ann Thorac Surg. 2002;73:480-9.

13. Filsoufi F, Rahmanian PB, Castillo JG, Chikwe J, Kini AS, Adams DH. Results and predictors of early and late outcome of coronary artery bypass grafting in patients with severely depressed left ventricular function. Ann Thorac Surg. 2007; 84:808-16.

14. Sabik JF, Blackstone EH, Houghtaling PL, Walts PA, Lytle BW. Is reoperation still a risk factor in coronary artery bypass surgery? Ann Thorac Surg. 2005; 80:1719-27.

15. Salomon NW, Page US, Bigelow JC, Krause AH, Okies JE, Metzdorff MT. Reoperative coronary surgery. Comparative analysis of 6591 patients undergoing primary bypass and 508 patients undergoing reoperative coronary artery bypass. J Thorac Cardiovasc Surg. 1990;100:250-9.

16. Christenson JT, Simonet F, Schmuziger M. The impact of a short interval $(<$ or $=1$ year) between primary and reoperative coronary artery bypass grafting procedures. Cardiovasc Surg. 1996;4:801-7.

17. He GW, Acuff TE, Ryan WH, He YH, Mack MJ. Determinants of operative mortality in reoperative coronary artery bypass grafting. J Thorac Cardiovasc Surg. 1995;110:971-8.

18. Yap CH, Sposato L, Akowuah E, Theodore S, Dinh DT, Shardey GC, et al. Contemporary results show repeat coronary artery bypass grafting remains a risk factor for operative mortality. Ann Thorac Surg. 2009;87:1386-91.

19. Ellis SG, Weintraub W, Holmes D, Shaw R, Block PC, King SB 3rd. Relation of operator volume and experience to procedural outcome of percutaneous coronary revascularization at hospitals with high interventional volumes. Circulation. 1997;95:2479-84.

20. Shubrooks SJ Jr, Nesto RW, Leeman D, Waxman S, Lewis SM, Fitzpatrick P, et al. Urgent coronary bypass surgery for failed percutaneous coronary intervention in the stent era: is backup still necessary? Am Heart J. 2001;142: 190-6.

21. Seshadri N, Whitlow PL, Acharya N, Houghtaling P, Blackstone EH, Ellis SG. Emergency coronary artery bypass surgery in the contemporary percutaneous coronary intervention era. Circulation. 2002;106:2346-50.

22. Tcheng JE, Lincoff AM, Sigmon KN, Lee KL, Kitt MM, Califf RM, et al. Randomised placebo-controlled trial of effect of eptifibatide on complications of percutaneous coronary intervention: IMPACT-II. Integrilin to Minimise Platelet Aggregation and Coronary Thrombosis-II. Lancet. 1997;349:1422-8.

23. Goa KL, Noble S. Eptifibatide: a review of its use in patients with acute coronary syndromes and/or undergoing percutaneous coronary intervention. Drugs. 1999; 57:439-62.

24. Patti G, Colonna G, Pasceri V, Pepe LL, Montinaro A, Di Sciascio G. Randomized trial of high loading dose of clopidogrel for reduction of periprocedural myocardial infarction in patients undergoing coronary intervention: results from the ARMYDA-2 (Antiplatelet therapy for Reduction of Myocardial Damage during Angioplasty) study. Circulation. 2005;111:2099-106.

25. Sjauw KD, Konorza T, Erbel R, Danna PL, Viecca M, Minden HH, et al. Supported high-risk percutaneous coronary intervention with the Impella 2.5 device, the Europella registry. J Am Coll Cardiol. 2009;54:2430-4.

26. Haan CK, O'Brien S, Edwards FH, Peterson ED, Ferguson TB. Trends in emergency coronary artery bypass grafting after percutaneous coronary intervention, 1994-2003. Ann Thorac Surg. 2006;81:1658-65. 


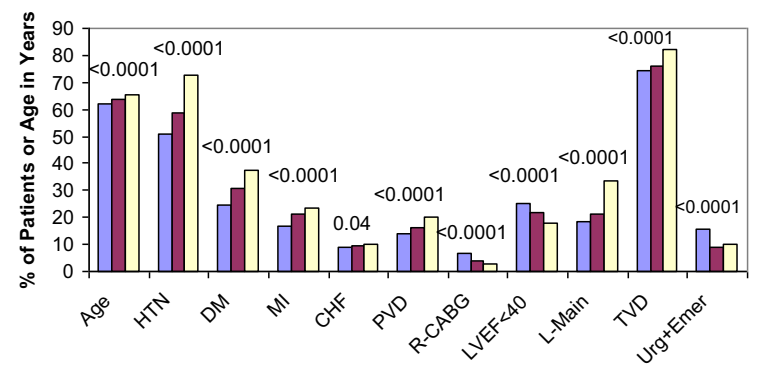

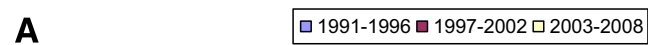

FIGURE E1. Risk profile of patients undergoing isolated coronary artery bypass grafting $(C A B G)$ stratified by era of surgery. Patient age, hypertension $(H T N)$, diabetes mellitus $(D M)$, preoperative myocardial infarction $(M I)$, congestive heart failure $(C H F)$, peripheral vascular disease $(P V D)$, left main disease (L-Main), and triple-vessel disease (TVD) increased significantly with time. Reoperative CABG $(R-C A B G)$, patients with poor left ventricular ejection fraction $(L V E F<40 \%)$, and urgent/emergency operations (Urg + Emerg) decreased significantly with time. $P$ values are included in the figure.

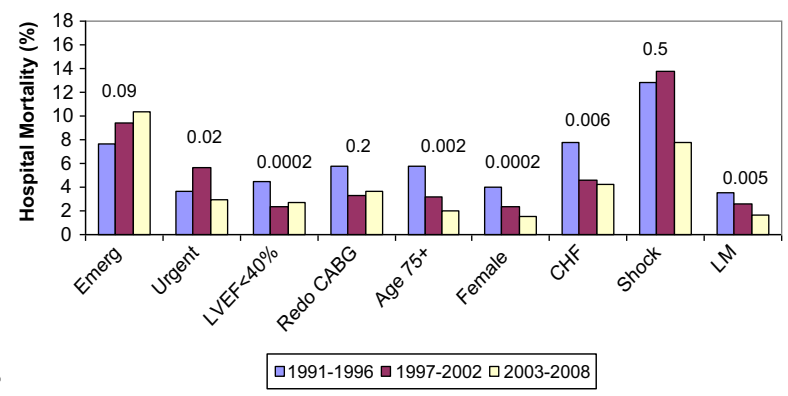

FIGURE E2. Observed operative mortality for all patients undergoing emergency (Emerg), coronary artery bypass grafting $(C A B G)$, urgent CABG (Urgent), patients with left ventricular ejection fraction ( $L V E F)$ less than $40 \%$, reoperative (Redo) CABG), patients 75 years or older, female patients, patients with congestive heart failure $(\mathrm{CHF})$, cardiogenic shock, and left main disease $(L M)$. $P$ values are included in the figure.

TABLE E1. Multivariable predictors of mortality in the entire cohort $(n=23,445)$

\begin{tabular}{|c|c|c|c|c|c|}
\hline Variable & $\mathbf{n}$ & Regression coefficient & OR & $95 \% \mathrm{CI}$ & $P$ value \\
\hline Constant & & $-9.36 \pm 0.48$ & & & \\
\hline Age* & - & $0.04 \pm 0.01$ & 1.0 & $1.0-1.1$ & $<.0001$ \\
\hline Female gender & 4,956 & $0.46 \pm 0.12$ & 1.6 & $1.3-2.0$ & $<.005$ \\
\hline Hypertension & 13,856 & $0.44 \pm 0.12$ & 1.6 & $1.2-2.0$ & .01 \\
\hline Cardiogenic shock & 289 & $0.69 \pm 0.24$ & 2.0 & $1.3-3.2$ & .004 \\
\hline Congestive heart failure & 2,190 & $0.61 \pm 0.14$ & 1.8 & $1.4-2.4$ & $<.0001$ \\
\hline Peripheral vascular disease & 3,869 & $0.56 \pm 0.12$ & 1.8 & $1.4-2.2$ & $<.0001$ \\
\hline Reoperative CABG & 1,108 & $1.09 \pm 0.16$ & 3.0 & $2.2-4.0$ & $<.0001$ \\
\hline Left main disease & 5,400 & $0.33 \pm 0.12$ & 1.4 & $1.1-1.8$ & .004 \\
\hline \multicolumn{6}{|l|}{ LVEF $\dagger$} \\
\hline$<20 \%$ & 609 & $1.43 \pm 0.23$ & 4.2 & $2.7-6.5$ & $<.0001$ \\
\hline $20 \%-40 \%$ & 4,534 & $0.69 \pm 0.16$ & 2.0 & $1.5-2.7$ & $<.0001$ \\
\hline $40 \%-60 \%$ & 9,584 & $0.39 \pm 0.15$ & 1.5 & $1.0-2.0$ & .008 \\
\hline \multicolumn{6}{|l|}{ Urgency of surgery } \\
\hline Semiurgent & 751 & $0.80 \pm 0.23$ & 2.2 & $1.4-3.5$ & .0004 \\
\hline Urgent & 2,537 & $0.80 \pm 0.15$ & 2.2 & $1.7-3.0$ & $<.0001$ \\
\hline Emergency & 200 & $1.50 \pm 0.32$ & 4.5 & $2.4-8.4$ & $<.0001$ \\
\hline Year of operation 1991-1996 & 8,280 & $-0.80 \pm 0.16$ & 2.2 & $1.6-3$ & $<.0001$ \\
\hline
\end{tabular}

$O R$, Odds ratio; $C I$, confidence interval; $C A B G$, coronary artery bypass grafting; $L V E F$, left ventricular ejection fraction. The area under the receiver-operator characteristic curve was 0.8 . The Hosmer-Lemeshow goodness-of-fit $P$ value was . 19 . *Age is a continuous variable. $\dagger$ Odds ratios were calculated by comparing against LVEF $\geq 60 \%$. $\ddagger$ Odds ratios were calculated by comparing against the 2003-2008 time cohort. 